\title{
DETERMINATION OF ANTIOXIDANT CAPACITY IN PLUCHEA INDICA LESS LEAVES EXTRACT AND ITS FRACTIONS
}

\author{
PAINI SRI WIDYAWATI ${ }^{1}$
}

${ }^{1}$ Food Technology Programme, Agricultural Technology Faculty, Widya Mandala Catholic University, Surabaya, East Java, Indonesia Email: wiwiedt@gmail.com

Received: 25 Feb 2016 Revised and Accepted: 22 Jul 2016

\section{ABSTRACT}

Objective: This study was conducted to determine the DPPH free radical scavenging activity of pluchea extract (PE) and its fraction (ethyl acetate (EAF), n-butanol (BF) and aqueous (AF)) and comparing with the its activity of control antioxidant, such as green tea (GE) and rosemary extracts (RE), $\alpha$-tocopherol succinate (ATS) and BHT.

Methods: The antioxidant activity was evaluated by the decrease in absorbance as the result of DPPH ${ }^{*}$ color change from purple to yellow at 517 nm by using a stopped-flow spectrometer UV-Vis. AE (antiradical efficiency) was a parameter more exactly used to measure the antioxidant power than $\mathrm{EC}_{50}$ (efficient concentration to reduce $50 \%$ of $\mathrm{DPPH}$ concentration). This parameter was determined by $\mathrm{EC}_{50}$ and $\mathrm{TEC}_{50}$ (the time needed to reach the steady state).

Results: PE and its fraction had free radical-scavenging activity compared with control antioxidant. Based on EC 50 , the orders of ability to scavenging DPPH radicals was determined as the EAF $\sim \mathrm{GE}>\mathrm{PE} \sim \mathrm{ATS} \sim \mathrm{RE} \sim \mathrm{AF}>\mathrm{BHT} \sim \mathrm{BF}$. The results were not exactly because BHT and ATS were potentially as a synthetic antioxidant. Therefore AE parameter was used to determine scavenging activity. The classification order of scavenging activity based on $\mathrm{AE}$ was $\mathrm{BHT}>\mathrm{GE} \sim \mathrm{ATS}>\mathrm{EAF}>\mathrm{RE} \sim \mathrm{BF} \sim \mathrm{PE} \sim \mathrm{AF}$.

Conclusion: The PE and its fractions had DPPH free radical scavenging activity. Based on EC $\mathrm{E}_{50}$ and AE parameters, the EAF showed the strongest DPPH free radical scavenging activity compared with PE and the other fractions.

Keywords: Antioxidant capacity, 2,2-diphenyl-1-picrylhydryzyl (DPPH), Pluchea leaves extract, Fractions

(C) 2016 The Authors. Published by Innovare Academic Sciences Pvt Ltd. This is an open access article under the CC BY license (http://creativecommons. org/licenses/by/4. 0/) DOI: http://dx.doi.org/10.22159/ijpps.2016v8i9.11410

\section{INTRODUCTION}

Pluchea indica Less, belonging to the family of Asteraceae, has been used as traditional medicine and food in Indonesia and Malaysia [1, 2]. Its leaf contains phytochemicals, such as phenol hydroquinone, tannin, alkaloid and sterol [3-5], flavonoid (quercetin, myricetin and kaemferol) [4-7], saponin and cardiac glycoside [4, 5]

The phytochemicals have an antioxidant activity to inhibit peroxidation reaction in food or the living body of humans, animals and plants $[8,9]$. Phenolic compounds have multifunctional and can act as reducing agents, free radical terminators, metal chelators and singlet oxygen quenchers [10]. All phenolic classes have the structural requirements of free radical scavengers and the potential as strong antioxidants $[11,12]$

Antioxidant activity is a complex process that can occur through several mechanisms. Due to the complexity test must be carried out to evaluate the antioxidant activity of pure compounds or extracts. One of the tests proposed for assessment of antioxidant activity (AOA) is DPPH freeradical colorimetry, whose color changes from purple to yellow in the presence of antioxidants [13]. The kinetics of decoloration reactions directly was related to the types and the different concentrations of antioxidants. The more rapidly the absorbance decreases, the more potentially the antioxidant activity donates hydrogen atom. The rapid reduction of $\mathrm{DPPH}^{*}$ radical by antioxidants is allowed the evaluation of antioxidant power of different antioxidants $[14,15]$. Substances which are able to perform this reaction can be considered as antioxidants and radical scavengers [16].

$\mathrm{EC}_{50}$ parameter is efficient concentration to reduce $50 \%$ of DPPH concentration that is used to determine antioxidant power of substances without involving reaction time between DPPH free radical and antioxidant compounds. AE (antiradical efficiency) is a parameter more exactly used to measure the antioxidant power than $\mathrm{EC}_{50}$ because this parameter involves reaction time to determine antioxidant capacity. AE is calculated by formulation:

$$
A E=\frac{1}{(\text { EC50 } \mathrm{TEC50)}} \text { (Equation 1) }
$$

This study was aimed to determine the DPPH free radical scavenging activity of pluchea extract (PE) and its fraction (ethyl acetate (EAF), n-butanol (BF) and aqueous (AF)) and comparing with the its activity of control antioxidant, such as green tea (GE) and rosemary extracts (RE), $\alpha$-tocopherol succinate (ATS) and BHT.

\section{MATERIALS AND METHODS}

\section{Chemicals and reagents}

Pluchea leaves were collected from a pluchea garden in Dramaga, Bogor, Indonesia. Dried green tea was supplied by a tea factory in Singapore (Lim Lam Thye PTE, LTD). Dried rosemary was purchased in Cold Storage Supermarket in Holland Avenue Singapore. Methanol, n-butanol, petroleum ether and ethyl acetate were purchased from Merck Company (Darmstadt, Germany). 1,1diphenyl-2-picrylhydrazyl free radical (DPPH), BHT (butylated hydroxytoluene) and $\alpha$-tocopherol succinate were purchased from Sigma-Aldrich Company Ltd. (Gillingham, UK).

\section{Sampling}

Pluchea indica less leaves were harvested from 1-6 age level [17] The leaves were dried at room temperature and ground to a fine powder (40 mesh). The moisture content was determined to be $10.38 \%$. And then dried leaves powder was mixed before extraction.

\section{Extraction and fractionation}

Extraction and fractionation of pluchea leaves were determined according to the method of [18] with slight modifications. The dried powder $(100 \mathrm{~g})$ of pluchea leaves was macerated with $400 \mathrm{ml}$ petroleum ether at room temperature for $24 \mathrm{~h}$ with constant stirring. The resulting extracts were filtered, and the residue was dried at ambient temperature and lyophilized. The dried residue 
$(10 \mathrm{~g})$ was extracted by soxhlet extraction with $150 \mathrm{ml}$ methanol. The PE was obtained by concentrating the supernatant using a rotary vacuum evaporator at $40^{\circ} \mathrm{C}$ (Laborota 4000, Heindolph, Germany) and freeze dried. The same process was repeated for dried green tea and rosemary to obtain GE and RE used as an antioxidant control. PE was dissolved in distilled water and then partitioned sequentially in two different solvents, namely EAF and $\mathrm{BF}$, respectively $(1: 1 \mathrm{v} / \mathrm{v})$, to fractionate the semipolar and polar compounds in the PE. And then the resulting solvent fractions were concentrated by a rotary vacuum evaporator at $40^{\circ} \mathrm{C}$ and the $\mathrm{AF}$ was concentrated by a rotary evaporator and freeze-dried. The PE and its fractions were stored in the dark at $4{ }^{\circ} \mathrm{C}$ before analysis.

\section{DPPH free radical-scavenging method}

The antioxidant activity of $\mathrm{PE}, \mathrm{EAF}, \mathrm{BF}$ and $\mathrm{AF}$ were measured in terms of hydrogen atom donating or radical scavenging ability, using DPPH free radical [19]. A methanolic solution $(150 \mu \mathrm{l})$ of each sample of various concentrations $(0.05-0.25 \mathrm{mg} / \mathrm{ml})$ was placed in a quartz cuvette, and $75 \mu \mathrm{l}$ of $\left(1 \times 10^{-4}\right) \mathrm{mmol} / \mathrm{l}$ methanolic solution of $\mathrm{DPPH}^{-}$was added. The mixture was measured for absorbance at 517 $\mathrm{nm}$ by using a stopped-flow spectrometer UV-Vis (MOS-200/M Spectrometer, Belgium). The decrease in absorbance was determined continuously with data detecting at one-second interval until a reaction reached a plateau. Methanol was used to zero a spectrophotometer (the negative control). The absorbance of the $\mathrm{DPPH}^{\circ}$ radical without antioxidant (i.e. the positive control) was measured daily. The calibration curve was presented as a mean value from the triplicate measurement. The $\mathrm{DPPH}^{\circ}$ concentration in the reaction medium was calculated from the following equation as determined by the linear regression:

$$
A 517 \mathrm{~nm}=10.111 x[D P P H]-0.011 \text {... }
$$

Where A was absorbance; [DPPH'] was DPPH concentration expressed in $\mathrm{mg} /$ liter; with $\mathrm{r}=0.9995$. The percentage of inhibition of the DPPH by the samples was calculated according to [20].

$$
\text { Inhibition }(\%)=\frac{(\mathrm{Ac}(0)-\mathrm{Ac}(\mathrm{t}))}{\mathrm{Ac}(0)} \times 100 \%
$$

Where $\mathrm{AC}(0)$ was the absorbance of the control at $t=0$ seconds and $\mathrm{AC}(\mathrm{t})$ was the absorbance of the antioxidant at $t$, which varied with the different concentrations.

\section{Statistical analysis}

All experiments were performed in triplicate. Data were presented as a mean value \pm standard deviation. $\mathrm{EC}_{50}$ and $\mathrm{TEC}_{50}$ values were estimated by linear regression. Statistical analyses were performed with the Excel and SPSS software package.

\section{RESULTS AND DISCUSSION}

Petroleum ether was non-polar solvent used to reduce lipid, wax, essential oil, and chlorophyll of pluchea leaves. Pluchea leaves contain essential oil [21, 22]. DPPH free radical scavenging activity of antioxidant tested was showed at fig. 1.

The results showed that the different types of antioxidants in samples and their concentrations caused the different absorbance of the $\mathrm{DPPH}^{-}$radical. Absorbance decreases a result of a color change from purple to yellow as the DPPH radical because antioxidant constituents donate a hydrogen atom to form the stable DPPH-H [13, $19,23]$. Verzelloni et al. (2007) said that all antioxidant samples don't have the same phenolic composition and all phenolics don't have the same antioxidant capacity. Hence, it is the quality and isn't the quantity of polyphenols that determines the antioxidant capacity of food.

Based on $\mathrm{IC}_{50}$ (inhibition concentration to reduce $50 \%$ of DPPH concentration), fig. 2 explained that GE and EAF had the same antioxidant activity for the similar concentration used. They were substantially more active than the other antioxidants at the same concentration. For GE and EAF, with $200 \mathrm{mg} / \mathrm{ml}$ concentrations, the bleaching ability of the DPPH solution was higher than $50 \%$, but PE, $\mathrm{BF}, \mathrm{AF}, \mathrm{ATS}$, and RE only had the bleaching ability lower than $50 \%$.

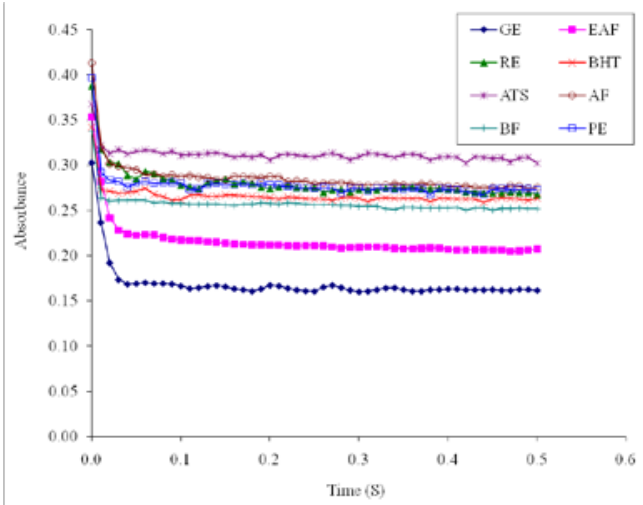

(a)

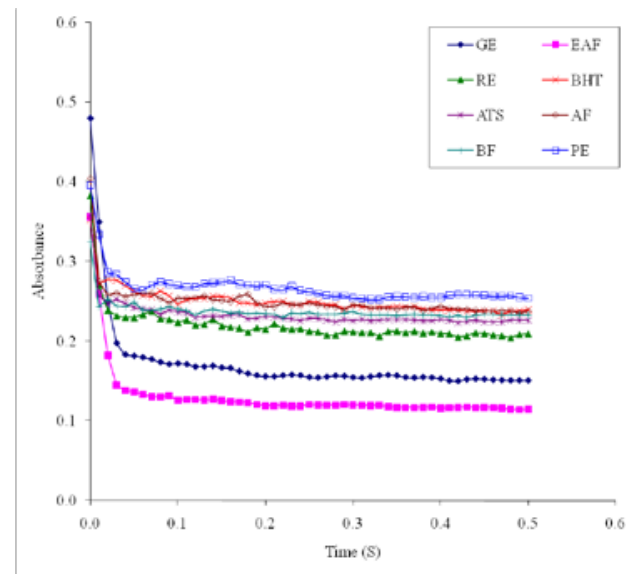

(b)

Fig. 1: Absorbance reduction of $75 \mu \mathrm{l}$ of $1 \times 10^{-4} \mathrm{~mol}^{\prime} \mathrm{l} \mathrm{DPPH}^{-}$in methanol plotted versus time from each tested sample (GE, RE, PE, EAF, AF, BF, BHT, and ATS) at concentration: a. $0.05 \mathrm{mg} / \mathrm{ml}$, b. $0.20 \mathrm{mg} / \mathrm{ml}$

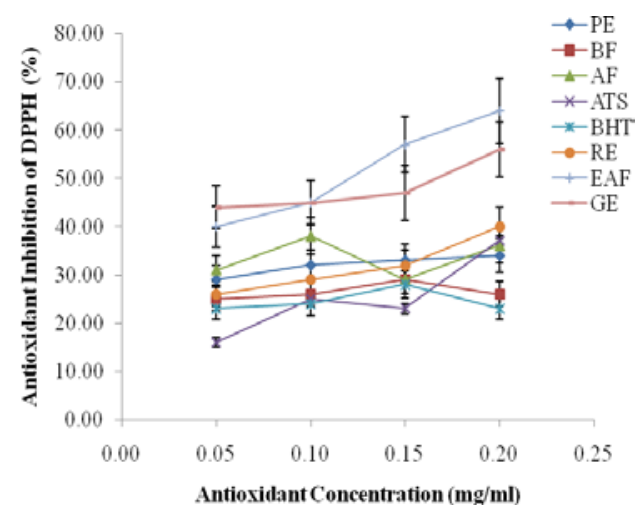

Fig. 2: Antioxidant inhibition of DPPH plotted versus antioxidant concentration of PE, EAF, AF, BF, GE, RE, BHT, and ATS at $200 \mathrm{mg} / \mathrm{ml}$ concentration

GE has high antioxidant activity because green tea contains high polyphenolic compounds including catechins, flavonols, flavanones, phenolic acids, glycosides and the aglycones of plant pigments [25] and microelements contributed as an antioxidant and free radicalscavenging properties. The active components of green tea can be extracted by solvent organic. Li et al. (2008) reported that the ethanolic extract possesses significantly higher DPPH free radical scavenging activity than the aqueous extract and $\alpha$-tocopherol. 
The higher inhibitor capacity of EAF than that of PE and other fractions (AF and BF) was caused by the different polarity of solvent used to extract antioxidant compounds. The different antiradical activity of PE and its fractions was related to intrinsic compounds. The different structure of phytochemical constituents determines scavenging activity. This argument is supported by [3, 6, 17, 27-31]. Widyawati et al. (2011) also informed that PE, BF and AF also contain phytochemical compounds the same as EAF, but AF hasn't founded sterol because it compound has different polarity.
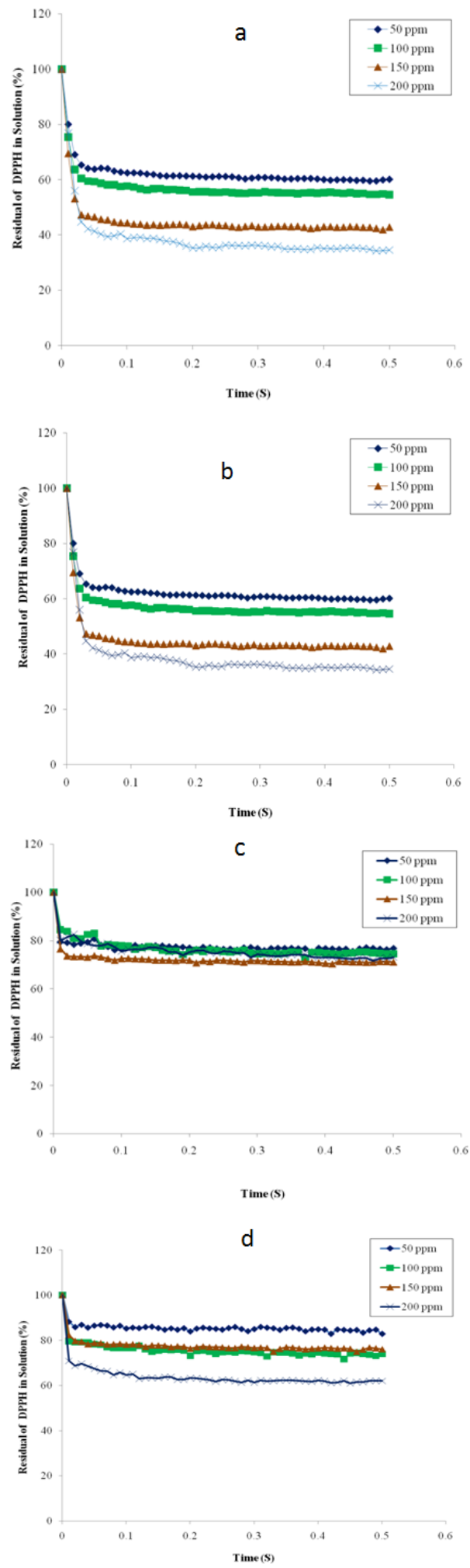
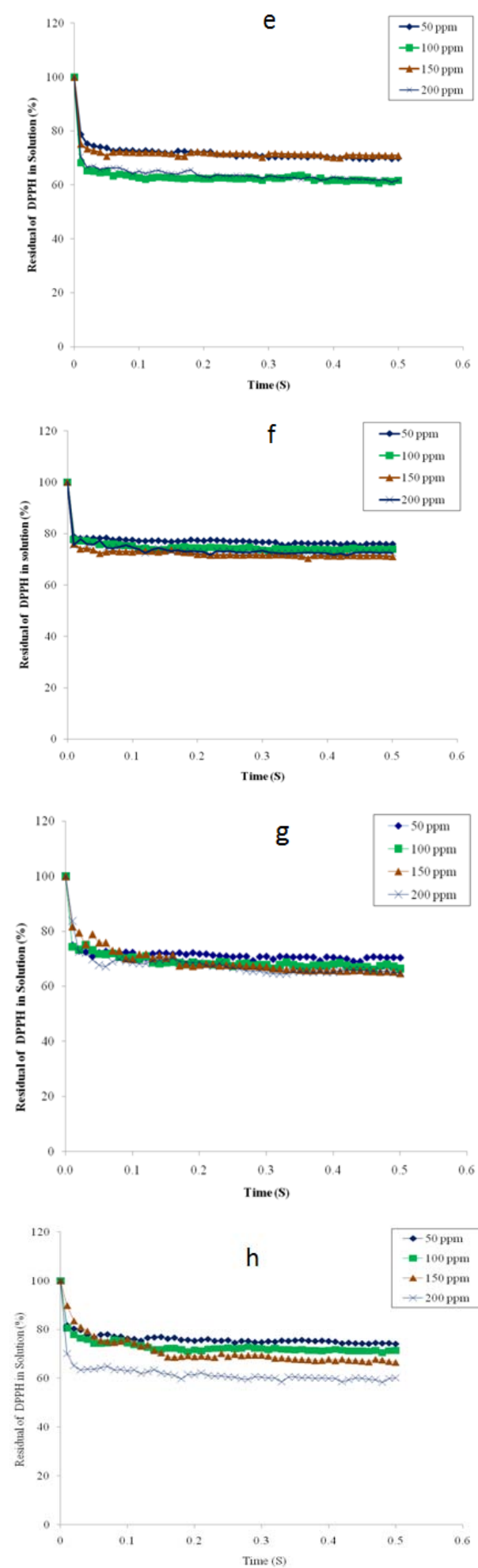

Fig. 3: Residual of DPPH in solution plotted versus time for concentrations of samples (a. GE, b. EAF, c. BHT, d. ATS, e. AF, f. $B F$, g. PE, h. RE) varying from 0.05 to $0.2 \mathrm{mg} / \mathrm{ml}$ at the steady state

The ethyl acetate-soluble components were the most effective electron donor compared with PE and the other fractions. Based on $\mathrm{IC}_{50}$ at fig. 2, the orders of ability to scavenging DPPH radicals was determined as the $\mathrm{EAF} \sim \mathrm{GE}>\mathrm{PE} \sim \mathrm{ATS} \sim \mathrm{RE} \sim \mathrm{AF}>\mathrm{BHT} \sim \mathrm{BF}$. Nevertheless, the order of antioxidant activity from PE, ATS, RE, and $\mathrm{AF}$ could not be determined. Data analysis showed hesitancy 
because BHT and ATS are a potentially synthetic antioxidant that can scavenge free radical.

\section{Fraction of the residual DPPH' solution plotted versus time}

The absorbance of the DPPH solution is decreased depending on the intrinsic antioxidant activity (AOA) of the antioxidant compounds as well as on the speed of the reaction between $\mathrm{DPPH}^{-}$and the antioxidant compounds [32].

In the case of rapid kinetic behavior, practically all samples at high concentrations were reacted within a very short time, and a steady state was reached almost immediately. The reaction kinetics depended on the concentration of the different samples. Samples with the highest concentration showed that the steady state was apparently reached at 0.06 seconds for GE, 0.19 seconds for EAF, 0.28 seconds for RE, 0.09 seconds for BHT, 0.12 seconds for ATS, 0.30 seconds for $\mathrm{AF}, 0.31$ seconds for $\mathrm{BF}$, and 0.11 seconds for $\mathrm{PE}$.

Data on the time course of absorbance (reaction kinetics) (fig. 1) enabled assessment of the extent of AOA for each sample. Therefore it was necessary to convert data on the reaction kinetics into new plots displaying the concentration of $\mathrm{DPPH}^{\circ}$ in solution as a function of time. The concentration of $\mathrm{DPPH}^{-}(\%)$ was calculated by equation 2 and 3. Fig. 3 was time-dependent plots of residual $\mathrm{DPPH}^{\cdot}$ for various concentrations of samples. From the different fig., the decrease in absorbance was a function of the concentration.

At the higher concentration, the greater was the decrease in absorbance. Using data from fig. 3, new plots can be constructed to display fractions of $\mathrm{DPPH}^{\cdot}$ residue in the solution at steady state condition as a function of sample concentration (mg antioxidant/g $\mathrm{DPPH}^{\circ}$ ) as showed in fig. 4.

At this stage, it is used a concept of efficient concentration $\left(\mathrm{EC}_{50}\right)$ defined as the amount of antioxidant concentration needed to reduce $50 \%$ of the initial $\mathrm{DPPH}^{\cdot}$ concentration, $\mathrm{C}_{\mathrm{DPPH}}(\mathrm{t}=0)$ by a factor of two (at steady state). The parameter $\mathrm{EC}_{50}$ is a direct quantitative measure for antioxidant activity (AOA); highly effective antioxidant is characterized by low $\mathrm{EC}_{50}$ value, and vice versa [23]. The $\mathrm{EC}_{50}$ values of the different samples taken into account were obtained from the plot of the absorbance against the concentrations and described in fig. 4.
Data showed that $\mathrm{EC}_{50}=49.14 \pm 4.81 \mathrm{mg} / \mathrm{g}$ for GE, $43.45 \pm 3.69 \mathrm{mg} / \mathrm{g}$ for $E A F, 80.38 \pm 8.28 \mathrm{mg} / \mathrm{g}$ for RE, $130.97 \pm 10.48 \mathrm{mg} / \mathrm{g}$ for BHT, $93.88 \pm 8.45 \mathrm{mg} / \mathrm{g}$ for ATS, $85.91 \pm 8.59 \mathrm{mg} / \mathrm{g}$ for AF, $117.65 \pm 11.53$ $\mathrm{mg} / \mathrm{g}$ for $\mathrm{BF}$ and $90.23 \pm 7.13 \mathrm{mg} / \mathrm{g}$ for PE. Based on $\mathrm{EC}_{50}$ at fig. 4, showed the orders of ability to scavenging DPPH radicals of samples tested similar to data based on $\mathrm{IC}_{50}$.

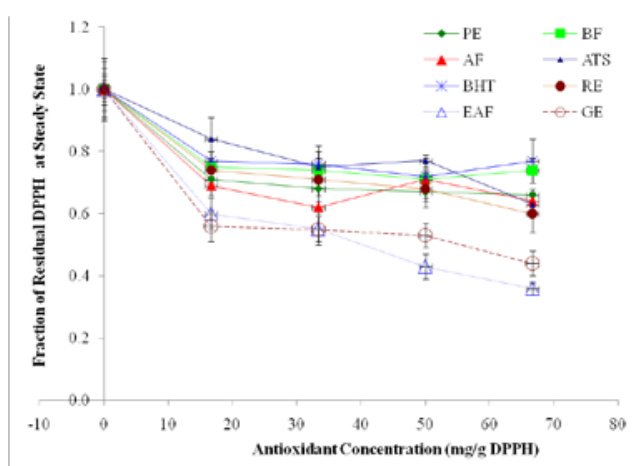

Fig. 4: Fraction of the residual DPPH' left at the steady state plotted versus antioxidant concentration

It means EAF was a potential antiradical. Antioxidant activity based on $\mathrm{EC}_{50}$ doesn't involve reaction time. Dawidowicz et al. (2012) said that parameter is considered to determine the antiradical activity of compounds including the $\mathrm{EC}_{50}$ and the time needed to reach the steady state $\left(\mathrm{TEC}_{50}\right) . \mathrm{EC}_{50}$ and $\mathrm{TEC}_{50}$ are calculated graphically affected the antiradical capacity. AE is calculated by equation 1 . The antioxidant had the lower the $\mathrm{EC}_{50}$ and the shorter the reaction time as the higher the antiradical efficiency. $\mathrm{AE}$ is a more adequate parameter for selecting antioxidants than the widely used $\mathrm{EC}_{50}$. Table 1 showed that EAF had the higher AE than PE and the other fractions, but its AE lower than it of BHT, GE, and ATS. Based on AE, BHT has been proven as a superior synthetic antioxidant. The classification order of $\mathrm{AE}$ for the tested antioxidants was $\mathrm{BHT}>\mathrm{GE} \sim$ $\mathrm{ATS}>\mathrm{EAF}>\mathrm{RE} \sim \mathrm{BF} \sim \mathrm{PE} \sim \mathrm{AF}$.

Table 1: The effective concentration of antioxidant compounds to inhibit 50\% DPPH and their antiradical efficiency

\begin{tabular}{|c|c|c|c|c|}
\hline Antioxidant & $\mathrm{EC}_{50}(\mathrm{mg} / \mathrm{g}$ DPPH$)$ & Range of time the steady state for antioxidant concentrations (s) & TEC $_{50}(\mathrm{~S})$ & $\mathbf{A E}$ \\
\hline GE & $49.14 \pm 4.81^{\mathrm{a}}$ & $0.08-0.22$ & 0.1224 & $0.1663 \pm 0.0166^{\mathrm{c}}$ \\
\hline EAF & $43.45 \pm 3.69^{a}$ & $0.19-0.28$ & 0.2224 & $0.1035 \pm 0.0088^{b}$ \\
\hline $\mathrm{RE}$ & $80.38 \pm 8.28^{\mathrm{b}}$ & $0.28-0.42$ & 0.2369 & $0.0525 \pm 0.0054^{\mathrm{a}}$ \\
\hline BHT & $130.97 \pm 10.48^{c}$ & $0.09-0.19$ & 0.0154 & $0.4943 \pm 0.0395^{d}$ \\
\hline ATS & $93.88 \pm 8.45^{\mathrm{b}}$ & $0.12-0.20$ & 0.0692 & $0.1540 \pm 0.0139 c$ \\
\hline $\mathrm{AF}$ & $85.91 \pm 8.59^{b}$ & $0.30-0.39$ & 0.2618 & $0.0445 \pm 0.0044^{\mathrm{a}}$ \\
\hline $\mathrm{BF}$ & $117.65 \pm 11.53^{c}$ & $0.31-0.45$ & 0.1656 & $0.05133 \pm 0.0050^{\mathrm{a}}$ \\
\hline PE & $90.23 \pm 7.13^{b}$ & $0.29-0.26$ & 0.2459 & $0.0451 \pm 0.0036^{\mathrm{a}}$ \\
\hline
\end{tabular}

Note: $\mathrm{EC}_{50}=$ effective concentration to inhibit $50 \% \mathrm{DPPH}, \mathrm{TEC}_{50}=$ the time needed to reach the steady state to $\mathrm{EC}_{50}$

$$
A E=1 /(E C 50 x T E C 50)
$$

The difference of antioxidant activity of PE and its fraction was related to structure-activity of some polyphenols. This is supported by [24]. DPPH free radical scavenging is determined by phenolic compounds capacity to donate hydrogen atom or electron and kinetic reaction between phenolic compounds and DPPH free radical. Polyphenolic compounds with aglycon structure could donate hydrogen atom or electron higher than those with glycoside structure. Sanchez-Moreno et al. (1998) also reported that monophenols need less process to reach time at steady state. The higher antiradical capacity of EAF than $\mathrm{PE}$ and the other fractions was predicted that phytochemical contained was aglycon structure and medium polarity. Deng et al. (2011) informed that the antioxidant power is influenced by the capacity to prevent the autoxidation of free radical-mediated oxidation of the substrate in low concentration and the resulting radical after scavenging must be stable.

\section{CONCLUSION}

Pluchea extract (PE) and its fraction showed free radical scavenging activity compared with control antioxidant. Based on $\mathrm{EC}_{50}$ and $\mathrm{AE}$, EAF was more potentially as DPPH free radical-scavenging activity than $\mathrm{PE}$ and its other fractions. $\mathrm{AE}$ was exactly parameter to determine antioxidant activity of PE and the other fractions.

\section{ACKNOWLEDGEMENT}

The author thanks the Indonesian Government Funding for the financial support under the Sandwich Program in the National University of Singapore and the competitive research grant.

\section{ABBREVIATION}

Pluchea extract: PE, Rosemary extract: RE, n-Butanol fraction: BF, Alpha-tocopherol succinate: ATS, Aqueous fraction: AF, Green tea extract: GE, Efficient concentration at $50 \%$ inhibition: $\mathrm{EC}_{50}$, Ethyl 
acetate fraction: AF, Antioxidant activity: AOA, Antiradical efficiency: $\mathrm{AE}$, The time needed to reach the steady state to $\mathrm{EC}_{50}$ : $\mathrm{TEC}_{50,2,2-}$ diphenyl-1-picrylhydryzyl: DPPH

\section{CONFLICTS OF INTERESTS}

Author declares no conflicts of interest

\section{REFERENCES}

1. Raharjo I, Horsten SFAJ. Pluchea indica less beach plants. Med Poisonous Plants 2008;12:441-3.

2. Dalimarta S. Atlas Tumbuhan Obat Indonesia. Trubus Agriwidya. Jakarta. Indonesia; 2003.

3. Ardiansyah, Nuraida L, Andarwulan N. Antimicroba activity of pluchea leaves (Pluchea indica Less) and its activity stability of various concentration of salt and $\mathrm{pH}$. J Technol Food Industry 2003;14:90-7.

4. Widyawati PS, Budianta TDW, Kusuma FA, Wijaya EL. The difference of solvent polarity to phytochemical content and antioxidant activity of Pluchea indica less leaves extracts. Int J Pharm Pharm Res 2014;6:850-5.

5. Widyawati PS, Budianta TDW, Gunawan DI, Wongso RS. Evaluation antidiabetic activity of various leaf extracts of Pluchea indica less. Int J Pharm Pharm Res 2015;7:597-603.

6. Andarwulan N, Batari R, Sandrasari DG, Bolling B, Wijaya CH. Flavonoid content and antioxidant activity of vegetables from Indonesia. Food Chem 2010;121:1231-5.

7. Rukmiasih. Penurunan bau amis (off-odor) daging itik lokal dengan pemberian daun beluntas (Pluchea indica Less) dalam pakan dan dampaknya terhadap performa [disertasi] Institut Pertanian Bogor. Bogor. Indonesia; 2011.

8. Han J, Rhee KS. Antioxidant properties of selected oriental nonculinary/nutraceutical herb extracts as evaluated in raw and cooked meat. Meat Sci 2005;70:25-33.

9. Greathouse SR, Sawyera JT, Lamberta BD, Kattes DH. Topical application of rosemary can alter the surface color characteristics of beef strip loins during simulated retail display conditions. Eur Int J Sci Technol 2013;2:37-40.

10. Souza JNS. Antioxidant capacity of four polyphenol-rich Amazonian plant extracts a correlation study using chemical and biological in vitro assays. Food Chem 2008;106:331-9.

11. Lesjak MM. Juniperus sibirica burgsdorf. as a novel source of antioxidant and anti-inflammatory agents. Food Chem 2011;124:850-6.

12. Dua D, Srivastava NS. A study on antioxidant and anti-aging properties of few medical plants. Int J Pharm Pharm Sci 2016;8:344-7.

13. Vrchovska V. Antioxidative properties of tronchuda cabbage (Brassica oleracea L. var. costata DC) external leaves against $\mathrm{DPPH}$, superoxide radical, hydroxyl radical and hypochlorous acid. Food Chem 2006;98:416-25.

14. Pan Y. Antioxidant activity of a microwave-assisted extract of longan (Dimocarpus Longan Lour.) peel. Food Chem 2008;106:1264-70.

15. Deng J, Cheng W, Yang G. A novel antioxidant activity index (AAU) for natural products using the DPPH assay. Food Chem 2011;125:1430-5.

16. Hinneburg I, Dorman HJD, Hiltunen R. Antioxidant activities of extracts from selected culinary herbs and spices. Food Chem 2006;97:122-9.
17. Widyawati PS, Wijaya CH, Harjosworo PS, Sajuthi D. Evaluation of antioxidant activity from Pluchea indica Less leaves extract based on the difference of leaf segment. Rekapangan J 2011;5:1-14.

18. Dorman HJD, Hiltunen R. Fe(III) reductive and free radicalscavenging properties of summer savory (Satureja hortensis $L$.) extract and subfractions. Food Chem 2004;88:193-9.

19. Brand-Williams W, Cuvelier ME, Berset C. Use of a free radical method to evaluate antioxidant activity. Lebensmittel Wissenschaft Technologie 1995;28:25-30.

20. Yen GC, Duh PD. Scavenging effect of methanolic extracts of peanut hulls on free radical and active oxygen species. J Agric Food Chem 1994;42:629-32.

21. Traithip A. Phytochemistry and antioxidant activity of Pluchea indicia less. [thesis] Mahidol University. Thailand; 2005.

22. Widyawati PS, Wijaya CH, Harjosworo PS, Sajuthi D. Volatile compounds of pluchea indica less and ocimum basillicum linn essential oil and potency as antioxidant. Hayati J Biosci 2013;20:117-26.

23. Bortolomeazzi R, Verardo G, Liessi A, Callea A. Formation of dehydro diisoeugenol and dehydro- eugenol from the reaction of isoeugenol and eugenol with DPPH radical and their role in the radical scavenging activity. Food Chem 2010;118:256-65.

24. Verzelloni E, Tagliazucchi D, Conte A. Relationship between the antioxidant properties and the phenolic and flavonoid content in traditional balsamic vinegar. Food Chem 2007;105:564-71.

25. Danrong Z, Yuqiong C, Dejiang N. Effect of water quality on the nutritional components and antioxidant activity of green tea extracts. Food Chem 2009;113:110-4.

26. Li F. In vitro antioxidant and anticancer activities of ethanolic extract of selenium-enriched green tea. Food Chem 2008;111:165-70.

27. Houghton PJ, Raman A. Laboratory handbook for the fractionation of natural extracts. Chapman and Hall. New York; 1998.

28. Cowan MM. Plant product as antimicrobial agents. J Microbiol Rev 1999;12:564-82.

29. Biswas R. Isolation, purification and characterization of four pure compounds from the root extract of Pluchea indica less and the potentiality of the root extract and the pure compounds for antimicrobial activity. Eur Bull Drug Res 2005;3:63-70.

30. Liu J. The antioxidant and free-radical scavenging activities of extract and fractions from corn silk (Zea mays L.) and related flavone glycosides. Food Chem 2011;126:261-9.

31. Soeksmanto A, Hapsari Y, Simanjuntak P. Antioxidant content of parts of Mahkota dewa, Phaleria macrocarpa [Scheff] Boerl. (Thymelaceae). Bioversitas 2007;8:92-5.

32. Yang MED, Wang MEQ, Ke BEL, Jian BEJ, Ying T. Antioxidant activities of various extracts of lotus (Nelumbo nuficera Gaertn) rhizome. Asia Pacific J Clin Nut 2007;16:158-63.

33. Dawidowicz AL, Wianowska D, Olszowy M. On practical problems in the estimation of antioxidant activity of compounds by DPPH method (Problems in the estimation of antioxidant activity). Food Chem 2012;131:1037-43.

34. Sanchez-Moreno C, Larrauri JA, Saura-Calixto F. A procedure to measure the antiradical efficiency of polyphenols. J Sci Food Agric 1998;76:270-6.

\section{How to cite this article}

- $\quad$ Paini Sri Widyawati. Determination of antioxidant capacity in Pluchea Indica less leaves extract and its fractions. Int J Pharm Pharm Sci 2016;8(9):32-36. 